\title{
Cytotoxic Effects of Britannin on Acute and Chronic Myeloid Leukemia Cells Through Inducing p21-Mediated Apoptotic Cell Death
}

\author{
(1) Hassan MOHAMMADLOU1', (1) Maryam HAMZELOO-MOGHADAM², (1) Marzieh MOEINIFARD³ ${ }^{3}$ (1) Ahmad GHAREHBAGHIAN1,4* \\ 1Shahid Beheshti University of Medical Sciences, School of Allied Medical Sciences, Department of Laboratory Hematology and Blood Bank, Tehran, Iran \\ ${ }^{2}$ Traditional Medicine and Materia Medica Research Center and Department of Traditional Pharmacy, School of Traditional Medicine, Shahid Beheshti \\ University of Medical Sciences, Tehran, Iran \\ 3 Tarbiat Modares University, Faculty of Medical Sciences, Department of Clinical Biochemistry, Tehran, Iran \\ 4Shahid Beheshti University of Medical Sciences; Pediatric Congenital Hematologic Disorders Research Center, Tehran, Iran
}

\begin{abstract}
Objectives: Following the success of natural compounds for treating solid tumors, interest in applying such agents for treating hematologic malignancies has been fired up more strikingly. Thus far, anti-leukemic effects of several compounds have been examined in different leukemia cell lines, especially in acute lymphoblastic leukemia. The agent that has recently attracted tremendous attention is Britannin, which is derived from Inula aucheriana DC., a plant that grows in Iran (Azerbaijan) and Türkiye. In this study, we evaluated the effects of this compound in myeloid leukemia for the first time.

Materials and Methods: We treated chronic myeloid leukemia (CML)-derived K562 and acute myeloid leukemia (AML)-derived U937 cells with different concentrations of britannin. We used several assays, including trypan blue, 3-(4,5-Dimethylthiazol-2-yl)-2,5-diphenyltetrazolium bromide, bromodeoxyuridine/5-bromo-2'-deoxyuridine, flow cytometry, and quantitative real-time polymerase chain reaction analysis, to study anti-leukemic effects of the compound.

Results: Our results show that while britannin remarkably reduced the survival of both cell lines in a concentrations-dependent manner, it had cytotoxic effects neither on mouse fibroblast-derived L929 cells nor on normal peripheral mononuclear cells. Moreover, among the tested cell lines, the viability of CML-derived K562 cells was inhibited at higher concentrations of the compound compared with AML-derived U937 cells. We found that britannin induced apoptotic cell death in both cell lines by altering the expression of anti- and pro-apoptotic genes. Britannin also hampered proliferative capacity of the cells in a p21/p27-dependent manner.

Conclusion: Overall, we suggest that based on the lack of toxicity on the normal cells and valuable anti-leukemic activities, britannin could be a promising agent in the treatment strategies of both CML and AML. However, further investigations must more precisely study this compound's mechanism of action and evaluate its safety profile.
\end{abstract}

Key words: Acute myeloid leukemia, chronic myeloid leukemia, britannin, cytotoxic effects, apoptosis

\section{INTRODUCTION}

For a long time, herbal medicines have catered to the basic needs humans to treat various diseases such as cancer. The success of vinca alkaloids, a group of drugs isolated from the periwinkle plant; Catharanthus roseus (L.) G. Don, for treating hematologic malignancies -indeed- has begun a new era in terms of cancer treatment strategies. ${ }^{2}$ Thus far, many compounds provided from natural sources have found their way into the treatment of different human cancers. ${ }^{3}$ Curcumin, ${ }^{4}$ trabectedin, ${ }^{5}$ and resveratrol $^{6}$ are all-natural compounds that recently enjoyed unprecedented success for treating human cancers. Ergolid is another natural compound isolated from Inula oculus-christi L., which showed anti-leukemic effects in acute lymphoblastic leukemia (ALL)-derived cell lines. Also, Artemisia annua L. 
extract has been reported to not only to induce caspase-3dependent apoptosis in ALL cells, but also to increase the sensitivity of the leukemic cells to chemotherapeutic drugs. ${ }^{7}$ Bryonia aspera Steven ex Ledeb. extract has also been reported to have anti-proliferative and pro-apoptotic effects in ALL-derived Nalm-6 and REH cells. ${ }^{8}$ During the burgeoning success of these reports and the astonishing roles of natural compounds in treating hematologic malignancies, there is a consensus that natural compounds could probably change the paradigm of treatment in human leukemia. Recently, promising results have been published about the cytotoxic effects of britannin, a sesquiterpene lactone (SL), which is derived from Inula aucheriana DC., a plant that grows in Iran (Azerbaijan) and Türkiye. ${ }^{9-11}$

It has been declared that apart from the anti-inflammatory effects, there is the presence of $\alpha$-methylene- $\gamma$-lactone in sesquiterpene lactones (SLs) that endows their ability to induce cell death in cancer cells. ${ }^{12}$ For example, in breast cancer, Hamzeloo-Moghadam et al. $^{13}$ have reported that low concentrations of britannin reduced the viability of MCF-7 cells through the suppression of cyclin D1 and CDK4 protein. In another study, this compound exerted cytotoxic effects in hepatocarcinoma, breast cancer, and lung cancer ${ }^{9}$ Cui et al. ${ }^{14}$ also suggested that britannin induced apoptotic cell death in liver cancer cells. In the most recent study, Mohammadlou et al.15,16 reported anti-leukemic effects of britannin in ALL cells. The authors suggested that this compound induced G1cell cycle arrest and increased intracellular levels of reactive oxygen species (ROS) in ALL cell lines. Although many studies have been focused on anticancer effects of britannin, as far as we are aware, no study has evaluated the effects of this compound in myeloid leukemia cells and our study examined anti-leukemic effect of britannin in chronic myeloid leukemia (CML)-derived K562 and acute myeloid leukemia (AML)-derived U937 cells for the first time.

\section{MATERIALS AND METHODS}

\section{Britannin isolation}

1. aucheriana was collected and its scientific name was confirmed at the Herbarium of Traditional Medicine and Materia Medica Research Center (TMRC), Shahid Beheshti University of Medical Science (voucher number: TMRC 3173). To obtain britannin, $600 \mathrm{~g}$ of I. aucheriana dried powder was soaked with $n$-hexane (plant: solvent ratio, 1:10) for three days. After filtration, the same process was repeated with chloroform with the residue of the plant. Seven $g$ of the dried chloroform extract was set to vacuum liquid chromatography (silica gel 40-63 $\mu \mathrm{m}$; mobile phase: ethyl acetate and methanol); $400 \mathrm{mg}$ of the fraction eluted with EtOAc-MeOH (2: 1) was further processed by solid-phase extraction $(2.5 \times 7.5 \mathrm{~cm}$ silica gel $40-63 \mu \mathrm{m}$; mobile phase: dichloromethane, ethyl acetate, and methanol) to afford britannin (70 $\mathrm{mg}$ ).

\section{Cell culture}

To evaluate the effect of the britannin on AML and CML derived cell lines, we cultured U937 and K562 cells in RPMI1640 medium containing $10 \%$ fetal bovine serum, $50 \mathrm{mg} / \mathrm{mL}$ streptomycin, and $30 \mathrm{mg} / \mathrm{mL}$ penicillin in a humidified incubator, respectively. We treated the cells with different concentrations of the compound $(0-10 \mu \mathrm{M})$ for 24 and $48 \mathrm{~h}$. We also cultured L929 cells, a non-cancerous cell line derived from mouse fibroblasts, and peripheral mononuclear cells (PBMCs) as a control to determine the safety of the compound.

\section{Trypan blue assay}

After incubating $U 937$ and $\mathrm{K} 562$ cells with different concentrations of britannin $(0,3,5$, and $10 \mu \mathrm{M})$ for 24 and 48 $h$, we stained the drug-treated cells with trypan blue dye. After remaining for 2-3 min at room temperature, the number of viable cells was counted manually using a light microscope.

\section{3-(4,5-Dimethylthiazol-2-yl)-2,5-diphenyltetrazolium bromide (MTT) assay}

MTT assay was used to evaluate whether britannin could reduce metabolic activity of the leukemic cells. Drug-treated leukemic cells were exposed to $100 \mu \mathrm{L}$ MTT solution $(0.5 \mathrm{mg} / \mathrm{mL})$ and were incubated for $4 \mathrm{~h}$. After centrifugation and discarding the medium, $100 \mu \mathrm{L}$ dimethyl sulfoxide was added to each well and, then, absorbance of each sample was measured at $570 \mathrm{~nm}$ by an ELISA reader.

\section{Annexin-V/PI staining assay}

Annexin V-FITC staining was used to assess the effect of britannin on the induction of apoptosis in leukemic cells. Both cell lines were treated with the desired concentrations of the compound, and after $48 \mathrm{~h}, 5 \mu \mathrm{L}$ of annexin V-FITC dye was added to each sample. Leukemic cells were incubated in the dark for $15 \mathrm{~min}$ and the induction of apoptosis was evaluated using BD FACS Calibur (BD biosciences, SanJose, CA, USA). The Flowjo 7.6 software was used for data analysis.

\section{Gene expression analysis}

To study the alterations in gene expression, the first RNA was extracted from drug-treated leukemic cells using Trizol reagent. After evaluating the quality of the extracted RNAs by Nanodrop, cDNA was synthesized by TAKARA kit (Japan). Real-time polymerase chain reaction (RT-PCR) was performed using SYBR green PCR. ABL was the housekeeping gene in this study. The primers used to evaluate the expression of genes are shown in Table 1.

\section{Statistical analysis}

One-way ANOVA and post-hoc Tukey multiple comparisons were used for data analysis. All analyses were performed using SPSS software version 22. A $p$ value $<0.05$ was considered statistically significant.

\section{RESULTS}

Effects of britannin on the viability and the metabolic activity of U937 and K562 cells

To evaluate whether britannin could reduce the population of leukemic cells, two myeloid leukemia cell lines, U937 and K562, were treated with increasing concentrations of the 
Table 1. Nucleotide sequences of primers used for RT-PCR

\begin{tabular}{|c|c|c|c|c|}
\hline Gene & Accession number & Forward primer $\left(5^{\prime}-3^{\prime}\right)$ & Reverse primer $\left(5^{\prime}-3^{\prime}\right)$ & Size (bp) \\
\hline$A B L$ & NM-005157 & AGTCTCAGGATGCAGGTGCT & TAGGCTGGGGCTTTTTGTAA & 290 \\
\hline$p 21$ & NM-000389 & CCTGTCACTGTCTTGTACCCT & GCGTTTGGAGTGGTAGAAATCT & 130 \\
\hline$p 27$ & NM-004064 & AACGTGCGAGTGTCTAACGG & CCCTCTAGGGGTTTGTGATTCT & 139 \\
\hline Bax & NM-138761 & CGAGAGGTCTTTTTCCGAGTG & GTGGGCGTCCCAAAGTAGG & 242 \\
\hline PUMA & NM-014417 & GACCTCAACGCACAGTACGAG & AGGAGTCCCATGATGAGATTGT & 98 \\
\hline Bad & NM-004322 & CCCAGAGTTTGAGCCGAGTG & CCCATCCCTTCGTCGTCCT & 249 \\
\hline$B c l-2$ & NM-000633 & CGGTGGGGTCATGTGTGTG & CGGTTCAGGTACTCAGTCATCC & 90 \\
\hline$M C L-1$ & NM-021960 & AGAAAGCTGCATCGAACCAT & CCAGCTCCTACTCCAGCAAC & 183 \\
\hline$B C L-x l$ & NM-138578 & GAGCTGGTGGTTGACTTTCTC & TCCATCTCCGATTCAGTCCCT & 119 \\
\hline
\end{tabular}

RT-PCR: Real-time polymerase chain reaction

compound. The results of trypan blue assay showed that, while britannin reduced number of $U 937$ cells in a concentrationdependent manner, anti-leukemic effects of this compound on K562 cells were exerted at a concentration of $10 \mu \mathrm{M}$ (Figure 1A). Moreover, to confirm anti-leukemic effects of britannin on myeloid leukemia cell lines, we also evaluated effect of the compound on metabolic activity of the cells. MTT assay showed that britannin significantly reduced the metabolic activity of both $U 937$ and K562 cells (Figure 1B). In agreement with the results of the trypan blue exclusion, anti-leukemic effects of britannin were more potent in $U 937$ cells as the concentration of $5 \mu \mathrm{M}$ of this compound diminished metabolic activity of U937 cells by almost $50 \%$. However, a significant anticancer effect of britannin on K562 cells was observed at a concentration of 10 $\mu \mathrm{M}$ (Figure 1B). We also found that U937 cells with an inhibitory concentration $50\left(\mathrm{IC}_{50}\right)$ value of $3.9 \mu \mathrm{M}$ were more sensitive to britannin compared to $\mathrm{K} 562$ with an $\mathrm{IC}_{50}$ value of $8.1 \mu \mathrm{M}$ (Figure $1 A$, B). To check whether the compound at the mentioned concentrations had cytotoxic effects on normal cells, noncancerous $L 929$ cells, and PBMCs were treated with increasing concentrations of the compound (3, 5, and $10 \mu \mathrm{M})$. As presented in Figure $1 \mathrm{C}$, britannin had minimal effects on viability of both PBMCs and L929 cells, suggestive of safety of the compound. To better study anti-leukemic effects of britannin on leukemic cell lines, we decided to treat $\mathrm{K} 562$ cells with 5,7 , and $9 \mu \mathrm{M}$ concentrations of the compound and $U 937$ cells with 3,5 , and 7 $\mu \mathrm{M}$ of britannin for further analysis.

\section{Effects of britannin on the proliferation of the leukemic cells}

Having established that britannin has anti-leukemic effects on K562 and U937 cells, we evaluated effect of the compound on proliferation of the cells. We treated K562 and U937 cells with different concentrations of the compound (0-9 $\mu \mathrm{M})$, and then DNA synthesis rate was determined using the bromodeoxyuridine/5-bromo-2'-deoxyuridine (BrdU) assay. Our results showed that britannin could reduce capacity of the leukemic cells to replicate DNA (Figure 2A). In agreement with this finding, we also found that britannin could reduce the expression of both p21 and p27 in both cell lines (Figure 2B).
Britannin induced apoptotic cell death in K562 and U937 cells

To determine whether the treatment of cell lines with britannin could induce apoptotic cell death, we treated both cell lines with different concentrations of the compound (0-9 $\mu \mathrm{M})$ and then binding of annexin- $\mathrm{V}$ combined with $\mathrm{PI}$ was analyzed by flow cytometry. As presented in Figures $3 A$ and $B$, we found a significant elevation in the percentage of annexin- $V$ and annexin-V/PI double-positive cells compared to the control group. In agreement with the MTT and trypan blue assay results, U937 cells were more sensitive to britannin than K562 cells. Moreover, to confirm these results, we also evaluated effect of the compound on expression of both anti- and pro-apoptotic genes. The results of the quantitative RT-PCR analysis indicated that while britannin could remarkably increase the expression levels of pro-apoptotic genes, including Bax, Bad, and PUMA, it could reduce the expression of anti-apoptotic genes such as $B c l 2, B C l-x l$, and $M C L-1$ (Figure 4).

\section{DISCUSSION}

From the first description of human leukemia until now, efforts were made to find a proper treatment for this type of disease. However, the heterogeneity between different sub-types of leukemia, whether they are categorized as chronic leukemia or acute leukemia, did not lead to the development of a single treatment regimen for both disease. ${ }^{17}$ For example, while CML takes advantage of tyrosine kinase inhibitors such as imatinib for treatment, ${ }^{18} \mathrm{AML}$ is mainly treated with vincristine, daunorubicin, and other conventional chemotherapeutic drugs. $^{19}$ Even targeted therapies also fail to introduce one specific small-molecule inhibitor to treat both acute and CML. ${ }^{17}$ Another challenge of the current treatment of human leukemia is the incidence of severe side effects for the patients, which eventually restrict the clinical dosage of the agents, an event that leads to the disease relapse. ${ }^{20,21}$ A stream of efforts for finding new agents with more potent anti-leukemic effects and lower side effects is on the way. Attention has also been attracted to herbal medicines, as many drugs isolated from plants have been shown to be safe and well-tolerated in clinical investigations. ${ }^{22}$ In this study, we evaluated the effect of britannin, a compound 

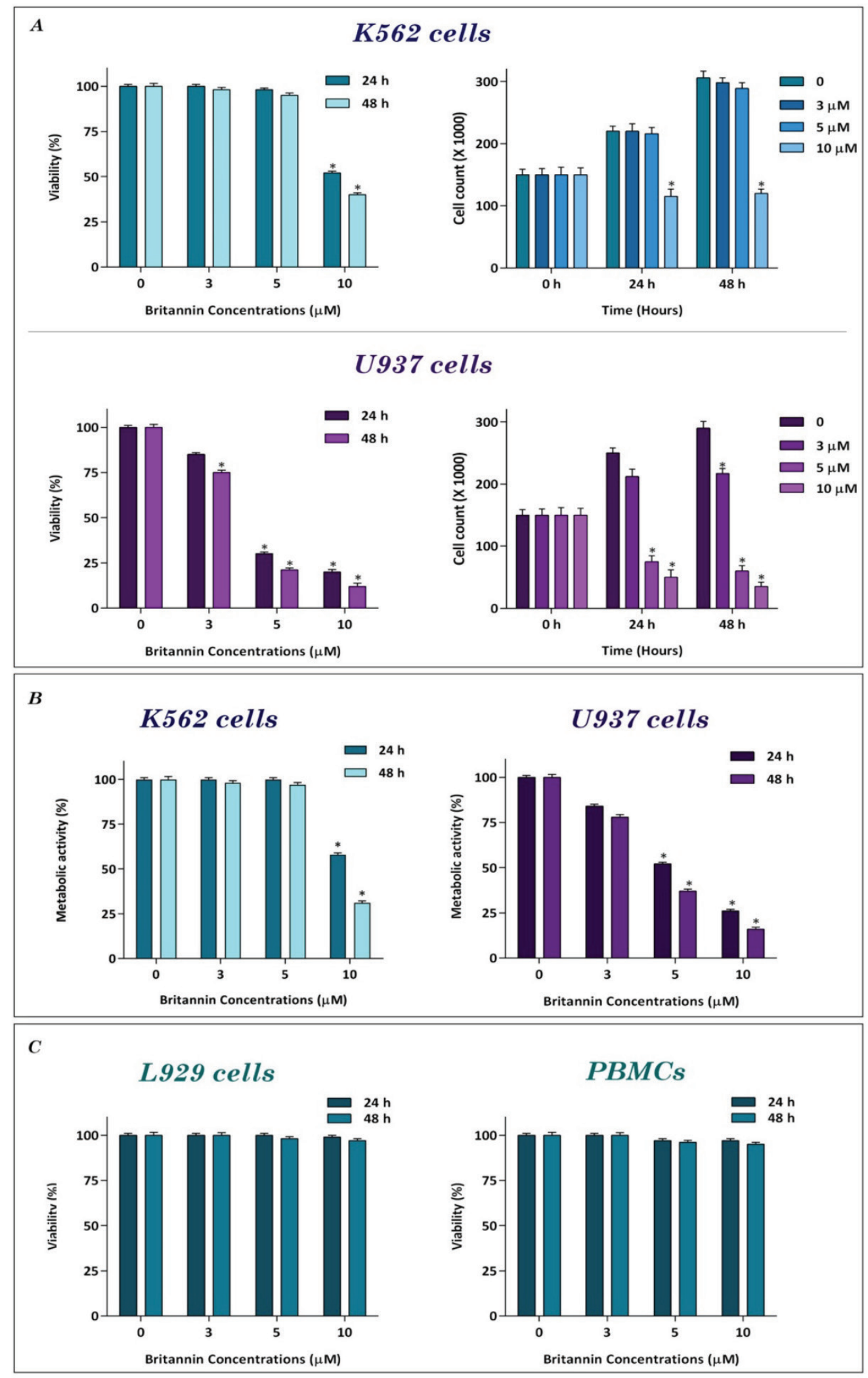

Figure 1. The effect of britannin on the viability and the metabolic activity of K562 and U937 cells. (A) Britannin concentrations of 3,5 , and $10 \mu \mathrm{M}$ significantly reduced the survival and number of viable cells in both leukemic cell lines. (B) The results of MTT assay revealed that britannin could hamper the metabolic activity of the cells in a concentrations-dependent manner. (C) Britannin at the concentrations of 3, 5, and $10 \mu \mathrm{M}$ had toxic effects neither on L929 cells or on PBMCs. Values are given as mean \pm SD of three independent experiments.

${ }^{*} p \leq 0.05$ represent significant changes from untreated control, MTT: 3-(4,5-Dimethylthiazol-2-yl)-2,5-diphenyltetrazolium bromide, PBMCs: Peripheral mononuclear cells, SD: Standard deviation 

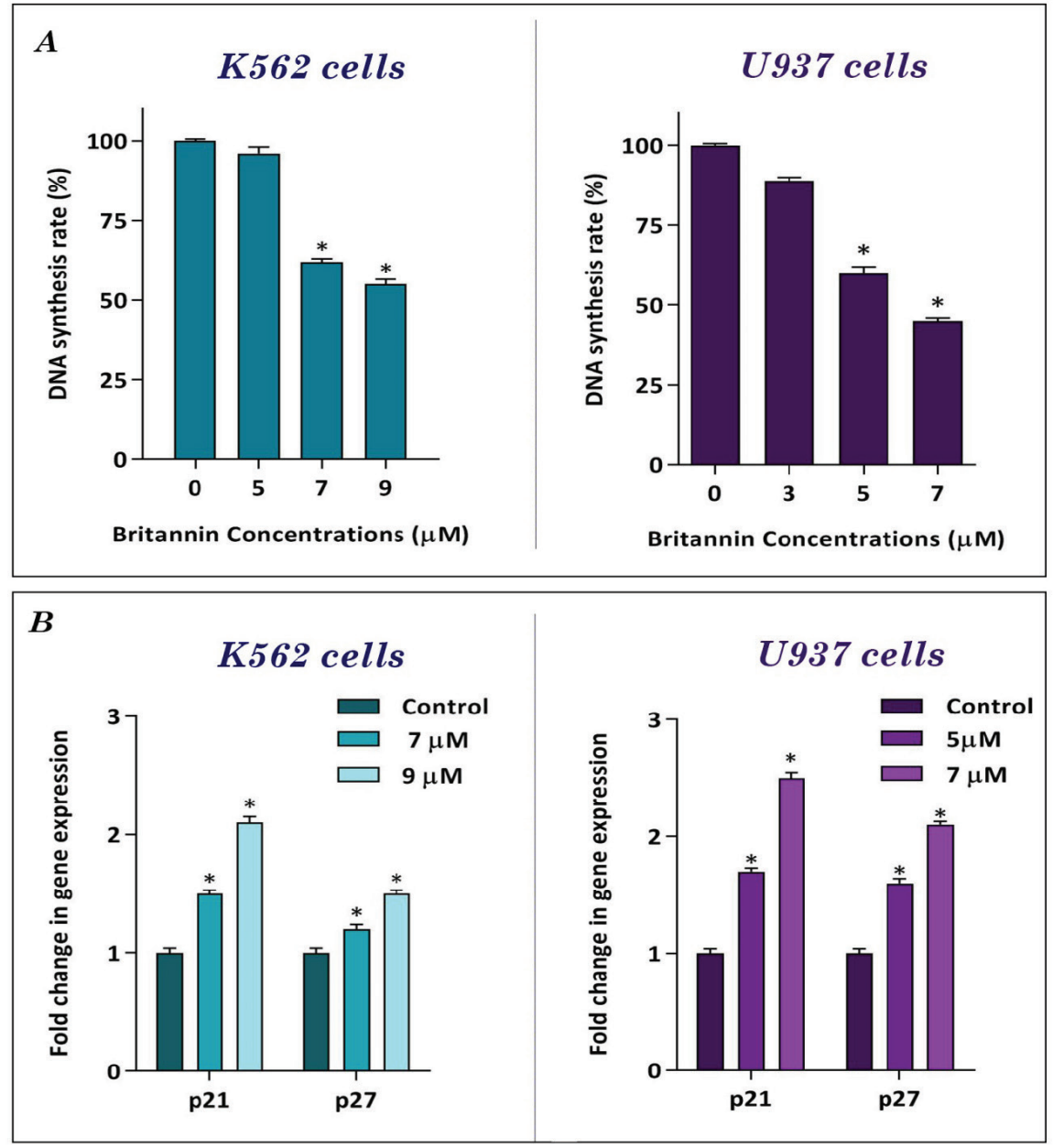

Figure 2. Anti-proliferative effects of britannin on K562 and U937 cells. (A) Treatment of K562 and U937 cells with increasing concentrations of britannin led to a decrease in the DNA synthesis rate of the cells. (B) Britannin significantly increased the expression of p21 and p27 in both cell lines. Values are given as mean $\pm \mathrm{SD}$ of three independent experiments

${ }^{*} p \leq 0.05$ represent significant changes from untreated control, SD: Standard deviation

isolated from I. aucheriana, on two myeloid leukemia cell lines, e.g. K562 and U937, which are derived from CML and patients with AML, respectively.

Interestingly, our results showed that britannin remarkably reduced the number of viable cells, cell growth, and metabolic activity of U937 cells in a concentration-dependent manner. However, for K562 cells, a significant anti-leukemic effect of the compound was obtained at a higher concentration $(10 \mu \mathrm{M})$. This finding suggested that, compared with U937 cells, CML-derived K562 cells were more resistant to the lower concentrations of britannin. Our results also showed that this single compound at the same concentrations had neither cytotoxic effects on L929 cells nor normal PBMCs.

Note that among the tested cell lines, we found that viability of CML-derived $\mathrm{K} 562$ cells was inhibited at higher concentrations of the drug, as compared with AML-derived U937 cells. This difference in cell sensitivity could be due to the excessive activation of PI3K/Akt signaling pathway in K562 cells because of the presence of BCR-ABL. ${ }^{23}$ It has been well-established that the PI3K/Akt activity could induce the drug-resistance in CML cells. ${ }^{24,25}$ However, britannin reduced survival of $\mathrm{K} 562$ cells at concentrations that had no toxic effects on the normal cells.

Having established anti-leukemic activity of britannin on both leukemic cell lines, we also examined the mechanism through, which this compound might induce its effects. Our results showed that britannin reduced the capability of the leukemic cells to replicate DNA. The results of the BrdU assay revealed that in the presence of britannin, there was a significant decrease in the DNA synthesis rate in both K562 and U937 cells, which in turn hampered the ability of the cells to proliferate. Similarly, britannin concentration-dependently reduced the number of viable cells in both cell lines. In agreement with our finding, Zhang et al. ${ }^{26}$ also indicated that britannin could reduce proliferation of cancer cells. It has been indicated that britannin interacts with $c-M y c$ and thereby hampers the proliferative activity of PDL-1-positive T-cells in the tumor site, an event that in turn prevents the growth and metastasis of cancer cells. ${ }^{26}$ Proliferation of leukemic cells could be regulated via the alterations in the genes controlling the progression of the cell cycle. Thus 

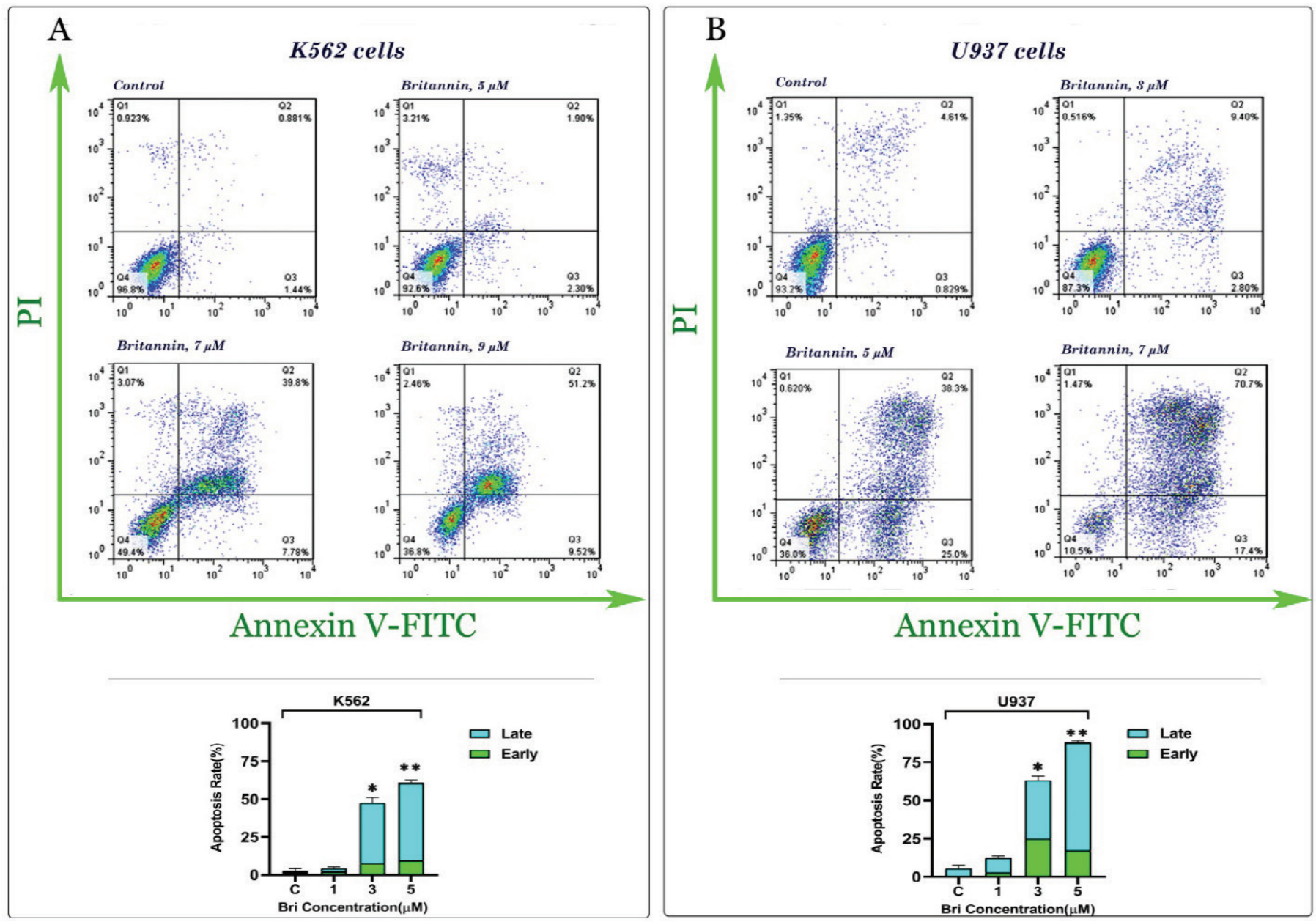

Figure 3. Britannin induces apoptotic cell death in leukemic cells. (A, B) Britannin elevated the percentage of both annexin- $\mathrm{V}$ and annexin- $\mathrm{V} / \mathrm{PI}$ doublepositive cells in $\mathrm{K} 562$ and $U 937$ cells. Values are given as mean \pm SD of three independent experiments

${ }^{*} p \leq 0.05$ represent significant changes from untreated control, SD: Standard deviation

far, several cell-cycle regulatory genes such as p21 and p27 have been identified. ${ }^{27}$ Moreover, the results of a previous study indicated that britannin could reduce the expression of cyclin D1 and CDK4, two other cell-cycle regulatory genes in breast cancer cells. ${ }^{13}$ In line with these results, we also found that britannin increased expression levels of both p21 and p27 in leukemic cell lines, suggesting that anti-proliferative capacity of britannin in K562 and U937 cells is mediated, at least in part, through altering the expression of the genes controlling the distribution of the cells in the cell cycle. Apart from regulating progression of the cells from G1 phase of the cell cycle to $S$ phase, p21 could also increase expression of pro-apoptotic genes such as Bax in the cells. ${ }^{28}$ It has also been declared that elevation in the expression of p21 could increase the sensitivity of cancer cells to apoptosis by increasing the expression of p53-related genes. ${ }^{29}$ In another study, Hastak et al. ${ }^{30}$ reported that ablation of p21 in prostate cancer cells prevented epigallocatechin-3-gallate, a polyphenolic compound of green tea, induced apoptotic cell death. In agreement with the up-regulation of p21, we found that not only britannin increased the expression of p53-dependent pro-apoptotic genes but also diminished the expression of anti-apoptotic genes such as BCl2, MCL-1, and $B C L-x l$. Moreover, this compound significantly increased the population of apoptotic cells in both K562 and U937 cells. Cui et al. ${ }^{14}$ also showed that this compound hampered viability of liver cancer cells by elevating the intracellular concentrations of reactive oxygen specious, which eventually induced apoptotic cell death. As the most straightforward interpretation of our results, we suggested that probably britannin reduced survival and proliferative capacity of myeloid leukemia cells via p21-mediated suppression of DNA synthesis and induction of apoptotic cell death.

\section{CONCLUSION}

Taken together, the results of this study indicated that based on minimal toxicity on the normal cells and valuable anti-leukemic activities, britannin could be introduced in the treatment strategies of leukemia, whether CML or AML. However, further investigations must more precisely investigate the mechanism 


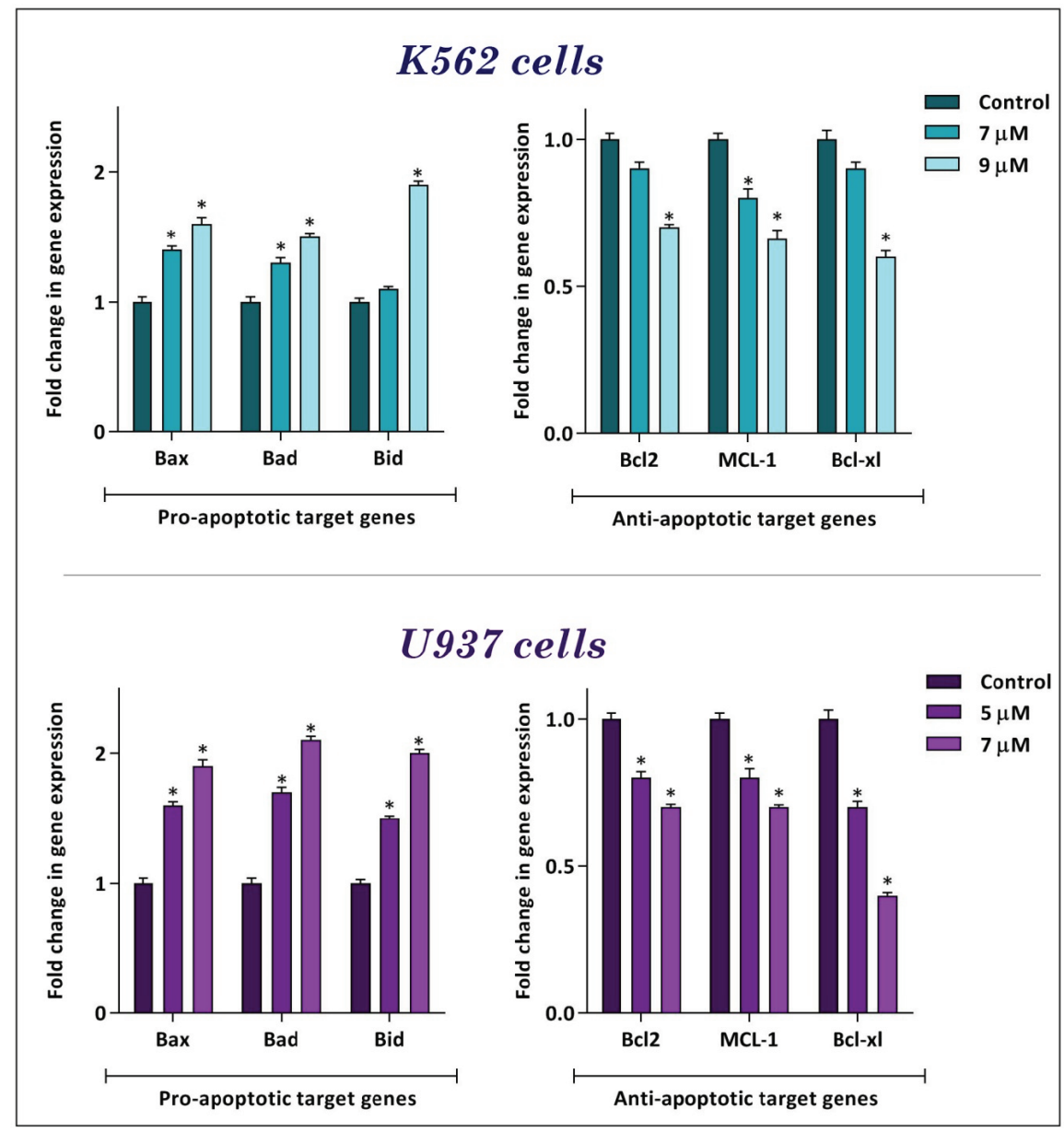

Figure 4. Britannin altered the expression of pro-and anti-apoptotic genes in K562 and U937 cells. The results of the qRT-PCR analysis showed that, while britannin elevated the expression of pro-apoptotic target genes, this compound diminished the expression of anti-apoptotic target genes in both cell lines. Values are given as mean \pm SD of three independent experiments

${ }^{*} p \leq 0.05$ represent significant changes from untreated control, qRT-PCR: Quantitative real-time polymerase chain reaction

of action of the compound and to evaluate its safety profile in a xenograft model.

\section{ACKNOWLEDGMENTS}

The authors would like to express their gratitude to Shahid Beheshti University of Medical Sciences (Tehran, Iran) for supporting this study.

\section{Ethics}

Ethics Committee Approval: The current study has been approved by the Ethics Committee of Shahid Beheshti University of Medical Sciences and its code of ethics is:1398.614

Informed Consent: The current study has been done on cell line and there was no need having informed consent.

Peer-review: Externally peer-reviewed.

\section{Authorship Contributions}

Concept: H.M., M.H.M., M.M., A.G., Design: H.M., M.H.M., M.M., A.G., Data Collection or Processing: H.M., M.H.M., M.M., A.G., Analysis or Interpretation: H.M., M.H.M., M.M., A.G., Literature
Search: H.M., M.H.M., M.M., A.G., Writing: H.M., M.H.M., M.M., A.G.

Conflict of Interest: No conflict of interest was declared by the authors.

Financial Disclosure: The current research had been financed by research committee of Shahid Beheshti University of Medical Sciences.

\section{REFERENCES}

1. Treasure J. Herbal medicine and cancer: an introductory overview. Semin Oncol Nurs. 2005;21:177-183.

2. Nobili S, Lippi D, Witort E, Donnini M, Bausi L, Mini E, Capaccioli S. Natural compounds for cancer treatment and prevention. Pharmacol Res. 2009:59:365-378.

3. Safarzadeh E, Sandoghchian Shotorbani S, Baradaran B. Herbal medicine as inducers of apoptosis in cancer treatment. Adv Pharm Bull. 2014;4(Suppl 1):421-427.

4. Sa G, Das T. Anticancer effects of curcumin: cycle of life and death. Cell Div. 2008;3:14. 
5. Krasner CN, Poveda A, Herzog TJ, Vermorken JB, Kaye SB, Nieto A, Claret PL, Park YC, Parekh T, Monk BJ. Patient-reported outcomes in relapsed ovarian cancer: results from a randomized phase III study of trabectedin with pegylated liposomal doxorubicin (PLD) versus PLD alone. Gynecol Oncol. 2012;127:161-167.

6. Athar M, Back JH, Tang X, Kim KH, Kopelovich L, Bickers DR, Kim AL. Resveratrol: a review of preclinical studies for human cancer prevention. Toxicol Appl Pharmacol. 2007;224:274-283.

7. Mashati P, Esmaeili S, Dehghan-Nayeri N, Bashash D, Darvishi M, Gharehbaghian A. Methanolic extract from aerial parts of Artemisia annua L. induces cytotoxicity and enhances vincristine-induced anticancer effect in pre-b acute lymphoblastic leukemia cells. Int $\mathrm{J}$ Hematol Oncol Stem Cell Res. 2019;13:132-139.

8. Yazdanpanah S, Esmaeili S, Bashash D, Dehghan Nayeri N, Esfini Farahani M, Gharehbaghian A. Cytotoxic and apoptogenic activity of Bryonia aspera extract on pre-B acute lymphoblastic leukemia cell lines. Int J Hematol Oncol Stem Cell Res. 2018;12:204-212.

9. Moghadam MH, Hajimehdipoor H, Saeidnia S, Atoofi A, Shahrestani R, Read RW, Mosaddegh M. Anti-proliferative activity and apoptotic potential of britannin, a sesquiterpene lactone from Inula aucheriana. Nat Prod Commun. 2012;7:979-980.

10. Chugunov PV, Sheichenko VI, Ban'kovskii Al, Rybalko KS. The structure of britannin-a sesquiterpene lactone from Inula britannica. Chem Nat Compd. 1971;7:265-268.

11. Bown D. The royal horticultural society. New encyclopedia of herbs and their uses. Dorling Kindersley Limited. 2002, Penguin Company, London.

12. Moeinifard M, Hassan ZM, Fallahian F, Hamzeloo-Moghadam M, Taghikhani M. Britannin induces apoptosis through AKT-FOXO1 pathway in human pancreatic cancer cells. Biomed Pharmacother. 2017;94:11011110.

13. Hamzeloo-Moghadam M, Aghaei M, Abdolmoham Madi MH, Fallahian F. Anticancer activity of britannin through the downregulation of cyclin D1 and CDK4 in human breast cancer cells. J Cancer Res Ther. 2019;15:11051108.

14. Cui $Y Q$, Liu YJ, Zhang F. The suppressive effects of britannin (Bri) on human liver cancer through inducing apoptosis and autophagy via AMPK activation regulated by ROS. Biochem Biophys Res Commun. 2018;497:916-923.

15. Mohammadlou $H$, Hamzeloo-Moghadam M, Mohammadi MH, Yami A, Gharehbaghian A. Britannin, a sesquiterpene lactone induces ROS-dependent apoptosis in NALM-6, REH, and JURKAT cell lines and produces a synergistic effect with vincristine. Mol Biol Rep. 2021;48:6249-6258.

16. Mohammadlou H, Hamzeloo-Moghadam M, Yami A, Feizi F, Moeinifard M, Gharehbaghian A. Britannin a sesquiterpene lactone from Inula aucheriana exerted an anti-leukemic effect in acute lymphoblastic leukemia (ALL) cells and enhanced the sensitivity of the cells to vincristine. Nutr Cancer. 2022;74:965-977.
17. DiNardo CD, Wei AH. How I treat acute myeloid leukemia in the era of new drugs. Blood. 2020;135:85-96.

18. Druker BJ, Guilhot F, O'Brien SG, Gathmann I, Kantarjian H, Gattermann N, Deininger MW, Silver RT, Goldman JM, Stone RM, Cervantes F, Hochhaus A, Powell BL, Gabrilove JL, Rousselot P, Reiffers J, Cornelissen JJ, Hughes T, Agis H, Fischer T, Verhoef G, Shepherd J, Saglio G, Gratwohl A, Nielsen JL, Radich JP, Simonsson B, Taylor K, Baccarani M, So C, Letvak L, Larson RA; IRIS Investigators. Five-year follow-up of patients receiving imatinib for chronic myeloid leukemia. N Engl J Med. 2006;355:2408-2417.

19. Roboz GJ. Current treatment of acute myeloid leukemia. Curr Opin Oncol. 2012;24:711-719.

20. Rubnitz JE, Gibson B, Smith FO. Acute myeloid leukemia. Hematol Oncol Clin North Am. 2010;24:35-63.

21. Goldman JM, Melo JV. Chronic myeloid leukemia-advances in biology and new approaches to treatment. N Engl J Med. 2003;349:1451-1464.

22. Fleischer T, Chang TT, Chiang JH, Sun MF, Yen HR. Improved survival with integration of Chinese herbal medicine therapy in patients with acute myeloid leukemia: a nationwide population-based cohort study. Integr Cancer Ther. 2017;16:156-164.

23. Kim JH, Chu SC, Gramlich JL, Pride YB, Babendreier E, Chauhan D, Salgia R, Podar K, Griffin JD, Sattler M. Activation of the PI3K/mTOR pathway by BCR-ABL contributes to increased production of reactive oxygen species. Blood. 2005;105:1717-1723.

24. Chen JR, Jia XH, Wang H, Yi YJ, Wang JY, Li YJ. Timosaponin A-III reverses multi-drug resistance in human chronic myelogenous leukemia K562/ADM cells via downregulation of MDR1 and MRP1 expression by inhibiting PI3K/Akt signaling pathway. Int J Oncol. 2016;48:2063-2070.

25. Chen Y, Wang T, Du J, Li Y, Wang X, Zhou Y, Yu X, Fan W, Zhu Q, Tong $X$, Wang $Y$. The critical role of PTEN/PI3K/AKT signaling pathway in shikonin-induced apoptosis and proliferation inhibition of chronic myeloid leukemia. Cell Physiol Biochem. 2018;47:981-993.

26. Zhang YF, Zhang ZH, Li MY, Wang JY, Xing Y, Ri M, Jin CH, Xu GH, Piao $L X$, Zuo HX, Jin HL, Ma J, Jin X. Britannin stabilizes T cell activity and inhibits proliferation and angiogenesis by targeting PD-L1 via abrogation of the crosstalk between Myc and HIF-1 $\alpha$ in cancer. Phytomedicine. 2021;81:153425.

27. El-Deiry WS. p21(WAF1) mediates cell-cycle inhibition, relevant to cancer suppression and therapy. Cancer Res. 2016;76:5189-5191.

28. Kang KH, Kim WH, Choi KH. p21 promotes ceramide-induced apoptosis and antagonizes the antideath effect of $\mathrm{Bcl}-2$ in human hepatocarcinoma cells. Exp Cell Res. 1999;253:403-412.

29. Aneja R, Ghaleb AM, Zhou J, Yang VW, Joshi HC. p53 and p21 determine the sensitivity of noscapine-induced apoptosis in colon cancer cells. Cancer Res. 2007;67:3862-3870.

30. Hastak K, Agarwal MK, Mukhtar H, Agarwal ML. Ablation of either p21 or Bax prevents $\mathrm{p} 53$-dependent apoptosis induced by green tea polyphenol epigallocatechin-3-gallate. FASEB J. 2005;19:789-791. 